\title{
Evaluation of the scarcity degree of water based on RWSI
}

\section{Yiming Sun}

School of Power engineering, North China Electric Power University, Huadian Street, Baoding, China; 364740356@qq.com

Keywords: Supply and Demand of water, RWSI, evaluating criterion.

\begin{abstract}
Water is a basic factor of the ecology, and is the irreplaceable physical base of human's being and development. In this paper, we predict the dynamic change of water resource under the present situation and intervention based on the relations between water demand and supply. We come up with the RWSI to evaluate the water supply and demand relations of a certain region or country, and formulate the corresponding evaluating criterion.
\end{abstract}

\section{Introduction}

In a specific area, different varieties of water make up the whole water system, and have explicit hierarchies and structures. In the water resource system, there exists atmosphere water, surface water, groundwater, and the treated sewage and the called in water from the outside of the system. According to the formation of the water resources and the transformation between the water resources, we can describe a certain area's water system. To deal with the relationships between the water resource supply and demand, we define the water resources in a certain water system as demand water and the supply water.

\section{Set up an Evaluation Index, RWSI}

\subsection{Water Demanded and Supplied and the Equations.}

According to the actual demand, we clarify the demanding water into: urban water demanding, rural water demanding and ecological and environmental water demanding. And the supplying water consists of the surface water availability, groundwater availability and other water availability, which is also showed as the figure 1.

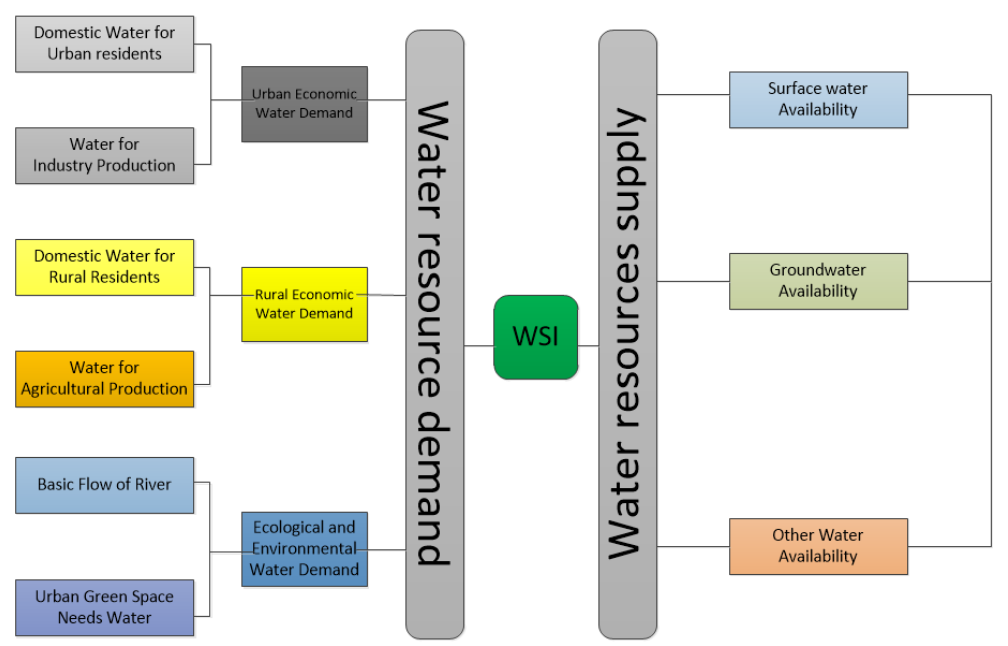

Figure 1:Water source system in a certain area

To judge the water resource bearing ability of the area, we quantitatively analyze the dynamic change from demanding and supplying availability.

2.2 The Resource of Supplied Water And Analysis 
1. The transferred method to supplied water can be described as figure 2 .

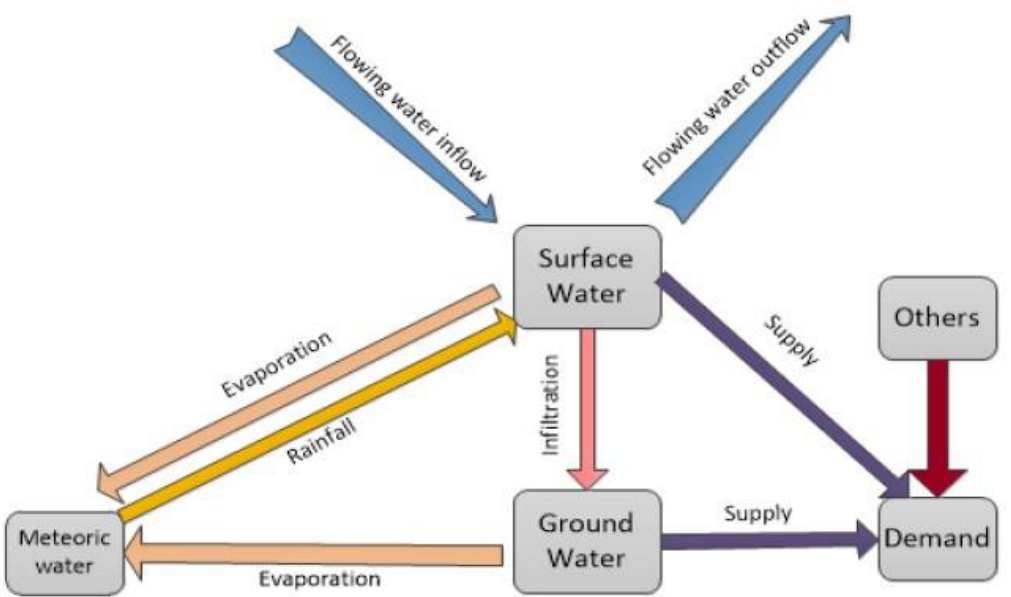

Figure 2: Origins and directions of water resources

The ways to count the amount of different varieties of water are listed:

The surface water:

Then we can get $\mathrm{SV}^{\mathrm{t}}$

$$
\Delta \mathrm{V}^{t}=I^{t}-S V^{t}+R^{t}-E^{t}
$$

In this equation, $V$ refers to the amount of the surface water, $I$ refers to the amount of rainwater supplement, $S V$ refers to the amount of water supply, $R$ refers to the flow supplement, $E$ refers to the evaporation and seepage loss.

The groundwater:

$$
\Delta \mathrm{GV}^{\mathrm{t}}=W-G S V^{t}-G E^{t}
$$

In this equation: $G V$ refers to the amount of groundwater, $W$ refers to the amount of penetration supplement, $G S V$ refers to the amount of water supply, $G E$ refers to the amount of evaporation loss

The other resources of water:

$$
\mathrm{MV}^{\mathrm{t}}
$$

Then, the total amount of supplied water is

$$
\mathrm{SW}=\mathrm{SV}+\mathrm{GSV}+\mathrm{MV}
$$

We define the per capita water occupancy volume is A. A refers to the available water resources on average to each person's possession.

We use the APW method, which is using the value of the A to judge the water scarcity degree:

Table 1: The international index of water resource shortage

\begin{tabular}{|c|c|}
\hline The value of $\mathrm{A}$ & Water Scarcity Degree \\
\hline $1700<\mathrm{A}<3000$ & Slight water shortage \\
\hline $1000<\mathrm{A}<1700$ & Moderate water shortage \\
\hline $500<\mathrm{A}<1000$ & Severe water shortage \\
\hline $\mathrm{A}<500$ & Extreme water shortage \\
\hline
\end{tabular}

In the table, APW $=\frac{\text { The Total Water Supply of the Region }}{\text { The Total Population of the Region }}$

The index of APW just reflects the relationship between the supplied water and the population. But it is hard to reflect the situation of the region that lacks of water and population. So we introduce a new method to reflect the water scarcity degree by the water supply and demand relations.

\subsection{The Resource of Demanded Water and Analysis}

1. Urban water demand.

(1) Domestic Water for Urban Residents

We use the Quota Method "1] to predict the urban demanded water. That is, we set the rational water availability that everyone use for a day, and combine with the total amount of population to predict the demanding water availability. The algorithm equation is showed as:

$$
\mathrm{W}_{\mathrm{UR}}^{t}=\mathrm{P}_{u}^{t} * Q_{u}^{t}
$$




$$
W_{r U R}^{t}=\frac{W_{U R}^{t}}{\eta_{u}}=\frac{P_{u}^{t} Q_{u}^{t}}{\eta_{u}}
$$

In this equation: $W_{U R}$ refers to the water consumption of urban residents, $P_{U}$ refers to the urban population, $Q_{U}$ refers to average water consumption, $\eta$ refers to the utilize rate of water consumption.

(2) Water for Industrial Production

$$
\begin{aligned}
& \mathrm{W}_{\mathrm{Id}}^{t}=\operatorname{Sev}^{t} * I Q^{t} \\
& W_{r l d}^{t}=\frac{W_{I d}^{t}}{\eta_{s}^{t}\left(1+R^{t}\right)}=\frac{\operatorname{Sev}^{t} * I Q^{t}}{\eta_{s}^{t}\left(1+R^{t}\right)}
\end{aligned}
$$

In this equation: $S e v$ refers to the added value of industry production, $I Q$ refers to the water consumption of industry production, $\eta$ refers to the utilize rate of water consumption, $R$ refers to the water repetition rate.

\section{Rural Water Demand}

(1) Domestic Water for Rural Residents

The way we calculate the amount of rural demanded water resembles the way we do when calculate the urban demanded water.

(2) Water for Agriculture Production

The water for agriculture production consists of water for farming crops and fishery, and the water for animal breeding.

The amount of water for farming crops can be calculated by

$$
\mathrm{W}_{\mathrm{Fc}}^{\mathrm{t}}=\sum \frac{A_{F i}^{t} * m_{F i}^{t}}{\eta_{F}^{t}}
$$

In this equation: $A_{F}$ refers to the farming area of the crop, $m_{F}$ refers to the unit irrigation amount of the crop i., $\eta$ refers to the efficiency of irrigation, The amount of water for fishery can be calculated by.

$$
W_{f}^{t}=w(E-P+S)
$$

$w$ refers to the area of the fish pond, $E$ refers to the amount of evaporation, $P$ refers to the amount of precipitation, $S$ refers to the amount of permeate.

The amount of water for animal breeding can be calculated by

$$
W_{A b}^{t}=\sum n_{i} * m_{i}
$$

$n$ refers to the amount of animal, $m$ refers to the average amount of water that animal drink.

3. Ecological and Environmental Water Demand.

(1) Basic Flow of River

Basic flow of river consists of the basic water needs outside the river and the Basic water needs inside the river.

Basic water needs inside the river refers to the water to maintain the river function. It consists of the water for economy flow, water for sediment transporting, and the water for aquatic organism. We can use the Tennant Method ${ }^{[2-5]}$ to calculate availability of basic flow river. The amount of water can be calculated by

$$
\mathrm{W}_{\mathrm{XSHN}}^{\mathrm{t}}=24 * 3600 * \sum_{i=1}^{12} M_{i} * Q_{i} * P_{i}
$$

Basic water needs outside the river refers to the water in river, the lake and the swamp, and can be calculated by the conservations of the amount of water.

$$
W_{X S}^{t}=S *\left(E_{W}-P\right)+F-R_{M}
$$

In this equation: $W$ refers to the to the basic water needs outside, $S$ refers to the area of the river, the lake and the swamp, $E$ refers to the amount of evaporation, $P$ refers to the amount of precipitation, $F$ refers to the amount ofpermeate, $R$ refers to the net flow of the system.

(2) Urban green space needs water

It can be calculated by 


$$
\mathrm{W}_{\mathrm{g}}^{t}=\sum \frac{A_{g i}^{t} * m_{g i}^{t}}{\eta_{g}^{t}}
$$

In this equation: $\mathrm{A}_{\mathrm{f}}$ refers to the area of the green space, $m_{F}$ refers to the unit irrigation amount of the green space, $\eta$ refers to the efficiency of irrigation.

Then we can know the total amount of demanded water is

$$
\mathrm{W}_{\mathrm{DW}}=\mathrm{W}_{\mathrm{rUR}}+W_{r I d}+W_{F C}+W_{f}+W_{A b}+W_{X S H N}+W_{X S}+W_{g}
$$

$W_{D W}$ refers to the total amount of demanded water.

To reflect the water shortage of the region, we define the parameter RWSI to describe the relationship between the demand and supply, and to evaluate the scarcity degree.

$$
R W S I=\frac{W_{D W}-S V}{W_{D W}}=1-\frac{S V}{W_{D W}}
$$

In the equation, RWSI is the water scarcity index of a region.

The evaluation criterion is showed in table 2

Table 2: Evaluating criterion of the water scarcity

\begin{tabular}{|c|c|}
\hline Water Scarcity Degree & RWSI $/ \%$ \\
\hline Basic water satisfaction & $<5$ \\
\hline Slight water shortage & $5 \sim 10$ \\
\hline Moderate water shortage & $10 \sim 20$ \\
\hline Severe water shortage & $>20$ \\
\hline
\end{tabular}

\section{Conclusion}

We set an equation of the total water consumption based on the multiple water demanders. Meanwhile, from the perspective of water supply, we obtain the total amount of water supply by the different sources of water. And then we come up with the APW and RWSI to reflect the shortage of water resource, and formulate the evaluating criterion.

\section{References}

[1]. Xin Yuan, En yang LI. With reference to the spatial variation of crop water requirement [J]. Journal of water conservancy, 1990,(2):33 37.

[2]. Tennant DL. In stream flow regimens for fish, wildlife, recreation, and related environmental resources, In: Orsborn J.F. and Allman C.H. eds. Proceedings of Symposium and Specialty ConferenceonInstream Flow Needs II .American Fisheries Society, Bethesda, Maryland, 1976. 359-373.

[3]. ZhongHP, LiuH, HuoLH. Reviewofassessment methods for instream mecological flowre quirements. Advancesin WaterScience, 2006, 17(3):430-434.

[4]. XuZX, Dong ZC, Zhou JK. Montana methodan ditsapplication incalculati onofecologica lwaterr equi rement, Water Resource sand Hydropower Engineering, 2003, 34(11):15-17. [5]Cui SB, Song SX. "Study on the Environmental Protection of yellow river below San menxia". Water Resources Protection Bureau of Yellow River Basin. [2002-04-23]. Water information net at http://www.hwcc.com.cn. 